\title{
Adsorption of proteins on spherical polyelectrolyte brushes in aqueous solution
}

\author{
A. Wittemann, B. Haupt and M. Ballauff*
}

Polymer Institut, University of Karlsruhe, Kaiserstrasse 12, 76128, Karlsruhe, Germany. E-mail: Matthias.Ballauff@chemie.uni-karlsruhe.de; Fax: +497216083153

We consider the adsorption of bovine serum albumin (BSA) on spherical polyelectrolyte brushes (SPB). The SPB consist of a solid polystyrene core of $100 \mathrm{~nm}$ diameter onto which linear polyelectrolyte chains [poly(acrylic acid), (PAA)] are grafted. The adsorption of BSA is studied at a $\mathrm{pH}$ of 6.1 at different concentrations of added salt and buffer. We observe strong adsorption of BSA onto the SPB despite the effect that the particles as well as the dissolved BSA are charged negatively. The adsorption of BSA is strongest at low salt concentration and decreases drastically with increasing amounts of added salt. Virtually no adsorption takes place at salt concentration of $0.1 \mathrm{M}$. Moreover, the adsorbed protein can be washed out again by raising the ionic strength from low to high values. A major driving force for the adsorption is located at a lower $\mathrm{pH}$ within the brush at low ionic strength. Thus, the isoelectric point of the protein may be approached or even reached. In this case strong interaction between the SPB and the protein results. Moreover, the negative charge of the polyelectrolyte interacts with the patches of positive charges on the protein. In this way the protein becomes a multivalent counterion within the brush and monovalent counterions will be released. All results demonstrate that the SPB present a new class of colloidal carrier particles whose interaction with proteins can be tuned in a well-defined fashion.

\section{Introduction}

The adsorption of proteins from solution to solid substrates is an important phenomenon. ${ }^{1}$ Often protein adsorption is to be avoided as, e.g., in the field of biocompatible materials. In this case the surface must be modified by suitable groups to resist protein adsorption. ${ }^{2}$ On the other hand, proteins may be immobilised on the surface of colloidal particles in order to obtain functional microspheres. ${ }^{3}$ Colloidal particles are wellsuited to study the adsorption of dissolved proteins to solid surfaces. These particles generate in solution a large surface area with well-defined properties. The process of adsorption onto the surface of the particles can therefore be easily monitored. Hence, there is a large number of studies of adsorption on silica particles, ${ }^{4,5}$ on latex particles ${ }^{3,6} 19$ or on AgI-particles. ${ }^{20}$ In general, the adsorption of proteins is a complex process and various driving forces as hydrophobic interaction, electrostatic interaction, and hydrogen bonding are discussed in literature. ${ }^{21}$ There is no clear picture yet, however, how the driving forces leading to protein adsorption can be changed in a predictable manner.

Here we discuss the interaction of dissolved proteins with colloidal particles onto which long polyelectrolyte chains have been grafted. Fig. 1 gives the schematic structure of these particles: the core particles consist of solid poly(styrene) onto which poly(acrylic acid) (PAA) chains are densely affixed. Hence, a polyelectrolyte brush ${ }^{22}$ has been generated on these strongly curved surfaces. The term brush denotes a system in which the average lateral distances between the polyelectrolyte chains are much smaller than their contour length. These particles are generated by photo-emulsion polymerization ${ }^{23}$ and have recently been studied comprehensively by dynamic light scattering (DLS). ${ }^{24,25}$ They are characterised in terms of the core radius $R_{\mathrm{C}}$, the contour length $L_{\mathrm{c}}$ of the grafted chains and the grafting density $\sigma$. These parameters are known

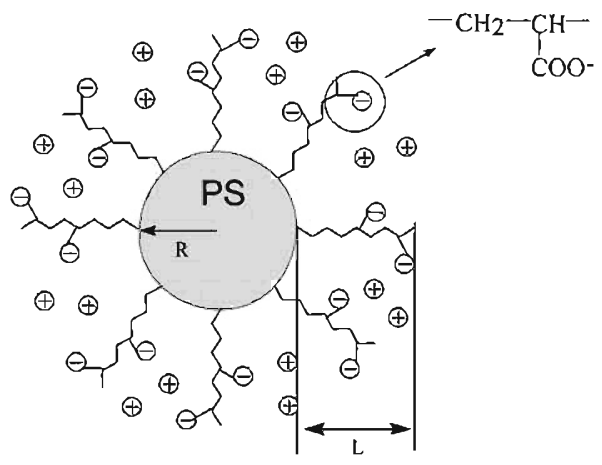

Fig. 1 Schematic presentation of a spherical polyelectrolyte brush (SPB). Long linear polyelectrolyte chains are grafted to a colloidal poly(styrene) sphere. The system studied here is an annealed SPB bearing chains of poly(acrylic acid). Hence, the number of charges per chain depends on the $\mathrm{pH}$ in the system. ${ }^{24,25}$

precisely and the particles hence present well-defined model systems for an investigation of the interaction of proteins with polyelectrolyte brushes.

Up to now only few studies of the adsorption of dissolved proteins to polyelectrolyte brushes have been available in literature. The only study on the adsorption of proteins to well-defined planar polyelectrolyte brushes was presented by Tran et al. recently. ${ }^{26}$ These authors investigated the adsorption of lysozyme and fibrinogen on a planar brush consisting of highly charged poly(styrenesulfonic acid) by neutron reflectivity. The positively charged lysozyme is irreversibly adsorbed to the negatively charged brush. This is to be expected and the resulting layered system is akin to the polyelectrolyte layers of alternating sign studied in great detail by G. Decher and coworkers. ${ }^{27}$ Surprisingly, Tran et al. found that the negatively 
charged fibrinogen is also strongly adsorbed to the brush. ${ }^{26}$ The authors explained this unexpected result by the specific interaction of the fibrinogen molecule with the sulfonate groups of the brush. The density profiles derived from the neutron reflectivity measurements demonstrated that the fibrinogen is located on the periphery of the brush, thus indicating a residual repulsion of the fibrinogen and the negatively charged chains.

In a series of papers, Saito et al. investigated the adsorption of proteins onto polymer chains grafted in to hollow fibers. ${ }^{28} 31$ A review of these investigations has been given recently. ${ }^{31}$ Saito et al. could demonstrate that the hollow fibers modified by polyelectrolyte chains are suitable for separation of proteins. These authors also showed that raising the ionic strength leads to less adsorption. A precise characterisation of the brush inside of the hollow fibers, however, is difficult.

Here we present the first study of the adsorption of bovine serum albumin (BSA) to the SPB depicted in Fig. 1. As SPB we use particles onto which PAA-chains have been grafted which form an annealed brush on the surface. The charge within the brush depends strongly on the $\mathrm{pH}$ in the system. ${ }^{24,25}$ The colloidal stability of these particles is excellent within a wide range of salt concentrations. The dependence of the process of adsorption on the electrostatic interaction can hence be investigated in a systematic fashion.

It should be noted that the particles used in this investigation are clearly different from the latexes studied so far. ${ }^{3} 19$ The surface properties of the SPB are dominated by long polyelectrolyte chains. Hence, the proteins are expected to interact mainly with the grafted chains. The grafting density on the surface of the particles is quite high so that the average distance between two polymer chains is smaller than the dimensions of the proteins. In this respect the SPB represent a novel system for the study of the adsorption and immobilisation of proteins akin to the planar polyelectrolyte brushes studied by Tran et al. recently. ${ }^{26}$

\section{Experimental}

The SPB were generated by affixing PAA-chains onto the surface. The SPB have been prepared by photo-emulsion polymerization. Details of the method of preparation and characterisation have been described elsewhere. ${ }^{23} 25$ The synthesis of these particles includes a careful ultrafiltration to remove all traces of free polymer.

The characterization of the SPB was done as described in ref. 23 and 24. The PAA chains have been cleaved off by strong base and analysed with regard to their molecular weight and molecular weight distribution. ${ }^{23}$ Two systems termed KpS13 and $\mathrm{KpS14}$ have been used in this study. Table 1 gathers the data characterizing the particles, namely: $R_{\mathrm{c}}$ radius of the core; $L_{\mathrm{cn}}, L_{\mathrm{cw}}$ number-average contour length of grafted chains and weight-average contour length, respectively; $\sigma$ grafting density of chains (calculated from the number-average contour length of the chains ${ }^{23}$ ).

The hydrodynamic radius $R_{\mathrm{H}}$ was determined by dynamic light scattering in dilute solution as described in ref. 23-25.

Table 1 Characterization of the spherical polyelectrolyte brushes

\begin{tabular}{llllll}
\hline $\mathrm{SPB}$ & $R_{\mathrm{o}} / \mathrm{nm}$ & $L_{\mathrm{cn}} / \mathrm{nm}$ & $L_{\mathrm{cw}} / \mathrm{nm}$ & $P$ & $\sigma / \mathrm{nm}^{-2}$ \\
\hline $\mathrm{KpS13}$ & 51 & 36 & 80 & 2.2 & 0.13 \\
$\mathrm{KpS14}$ & 50 & 30 & 53 & 1.7 & 0.13
\end{tabular}

$R_{\mathrm{c}}$ radius of the core; $L_{\mathrm{cn}}$ number-average contour length of grafted chains; $L_{\mathrm{Cw}}$ weight-average contour length of grafted chains; $P=$ $L_{\mathrm{cw}} / L_{\mathrm{cn}}, \sigma$ grafting density of chains.

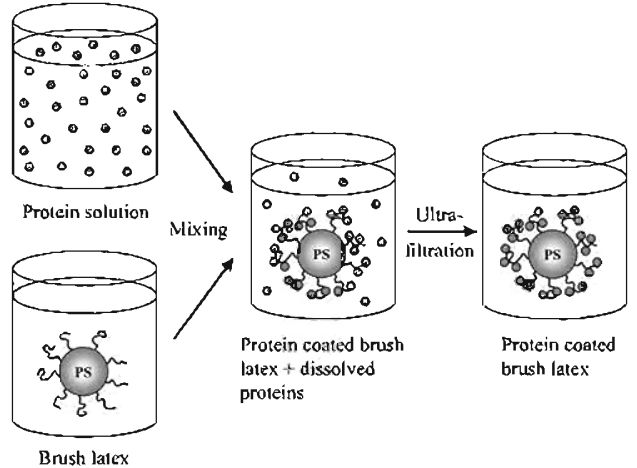

Fig. 2 Schematic representation of the experiment. Solutions of BSA were prepared in buffer solutions (MES) with defined concentrations of added salt. These solutions were added to the SPB dissolved in the same buffer. After equilibration for $24 \mathrm{~h}$ the non-adsorbed protein was removed by careful serum replacement.

All aqueous solutions of the SPB were carefully adjusted to a given ionic strength and $\mathrm{pH}$. Here we used $N$-morpholinoethanesulfonic acid (MES) that had been adjusted with $\mathrm{NaOH}$ to a $\mathrm{pH}$ of 6.1. In most investigations MES-concentrations of $10 \mathrm{mM}$ and $50 \mathrm{mM}$ have been used. Hence, in the case of a $10 \mathrm{mM}$ MES buffer, $5 \mathrm{mM} \mathrm{NaOH}$ had to be added. Higher ionic strengths were adjusted through an addition of $\mathrm{NaCl}$ to these solutions. In order to avoid possible microbial growth, $2 \mathrm{mM} \mathrm{NaN}_{3}$ were added to all solutions. Hence, the ion concentration is at least $7 \mathrm{mM}$; a higher ionic strength was adjusted through adding $\mathrm{NaCl}$ to the solutions.

Bovine serum albumin (BSA, fatty acids free, Sigma A-6003) was purchased from Sigma and used without further purification.

Fig. 2 summarizes the method employed here. Solutions of BSA were prepared in buffer solutions (MES) with defined concentrations of added salt. These solutions were added to the SPB in buffer solution (MES) and equilibrated for $24 \mathrm{~h}$. Thereafter the solutions were entered into a serum-replacement cell and flushed eight times with buffer solution of same $\mathrm{pH}$ and salinity. The amount of protein washed off by this procedure was determined spectroscopically from the known absorption coefficient. Subsequently, this figure and the total amount was used to calculate the amount of adsorbed BSA.

In all cases the same time of equilibration as well as the same procedure for serum replacement was used to ensure a meaningful comparison of the data. Additional experiments showed that no changes took place in the time scale of the present work-up procedure ( $c a .1$ day).

\section{Results and discussion}

\section{Characterisation of the SPB, titration curve}

In a number of recent publications, the SPB used in this study has been characterized thoroughly by dynamic light scattering (DLS). ${ }^{23} 25$ Moreover, osmometry ${ }^{32}$ demonstrated that the counterions are mostly confined within the brush as predicted by theory. ${ }^{22}$ For an annealed SPB the overall thickness $L$ (see Fig. 1) of the brush-layer on the surface of the particles depends on the $\mathrm{pH}$ as well as on the ionic strength in the solution. ${ }^{24,25}$ Fig. 3 shows a key result that demonstrates the marked influence of the $\mathrm{pH}$. Here, the brush thickness $L$ (open circles) is displayed as a function of the $\mathrm{pH}$. For this experiment the system L16 of ref. 24 has been used. $\left(R_{\mathrm{C}}=54 \mathrm{~nm}\right.$, $L_{\mathrm{c}}=209 \mathrm{~nm}, \sigma=0.054 \mathrm{~nm}^{2}$ ). The ionic strength used in this experiment is rather low $(10 \mathrm{mM})$. It is evident that the raising $\mathrm{pH}$ leads to a transition of a rather dense layer of virtually uncharged PAA-chains to a system of highly charged chains 


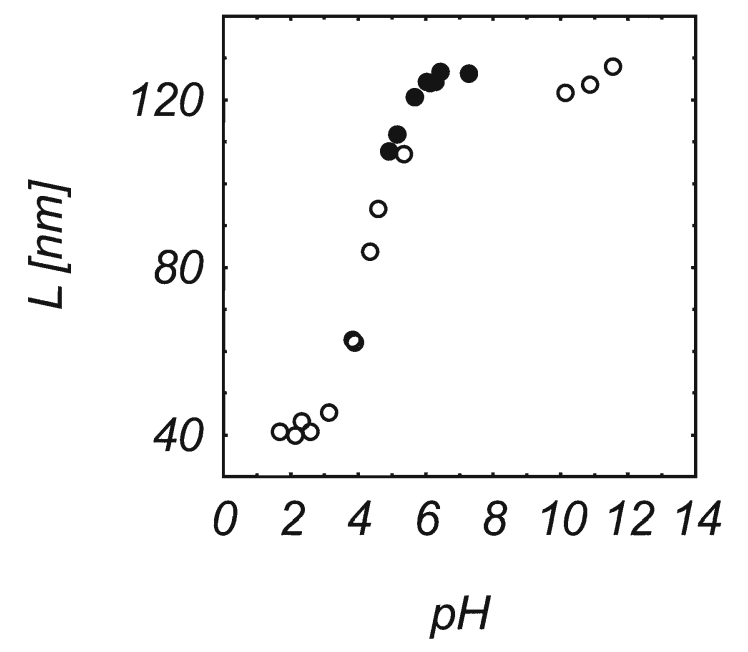

Fig. 3 Titration of an annealed SPB without MES (hollow circles) and in the presence of MES buffer (filled circles). The spherical polyelectrolyte system L16 used for this experiment was characterized recently in ref. 24 The ionic strength was kept to $10 \mathrm{mM}$ for all $\mathrm{pH}$.

stretched to nearly full length. This can clearly be seen in Fig. 3.

Fig. 3 demonstrates that the presence of the MES buffer does not change $L$ as the function of the $\mathrm{pH}$ (filled circles in Fig. 3). Here the $\mathrm{pH}$ has been changed in the neighbourhood of 6.1 while keeping the ionic strength constant $(10 \mathrm{mM})$. Fig. 3 shows that $L$ determined in the presence of MES coincides with the result obtained by adjusting the ionic strength in the system with $\mathrm{NaCl}$. This is a non-trivial finding inasmuch as MES is a zwitterionic system.

As already discussed at length in ref. 24 and 25, this strong stretching of the polyelectrolyte chains is brought about by the strong osmotic pressure of the counterions that are confined within the brush. ${ }^{32}$ The strong electric field of the polyelectrolyte chains just serves for keeping the ions inside the brush. ${ }^{22}$ The brush is hence in the "osmotic limit", i.e., its properties are governed by the osmotic pressure of the counterions confined within the brush layer.

If, however, the salt concentration is raised, the so-called "salted brush" results. ${ }^{22}$ Here the electrostatic interaction inside the brush layer is strongly screened. Such a system therefore resembles uncharged brushes. Fig. 4 demonstrates that the

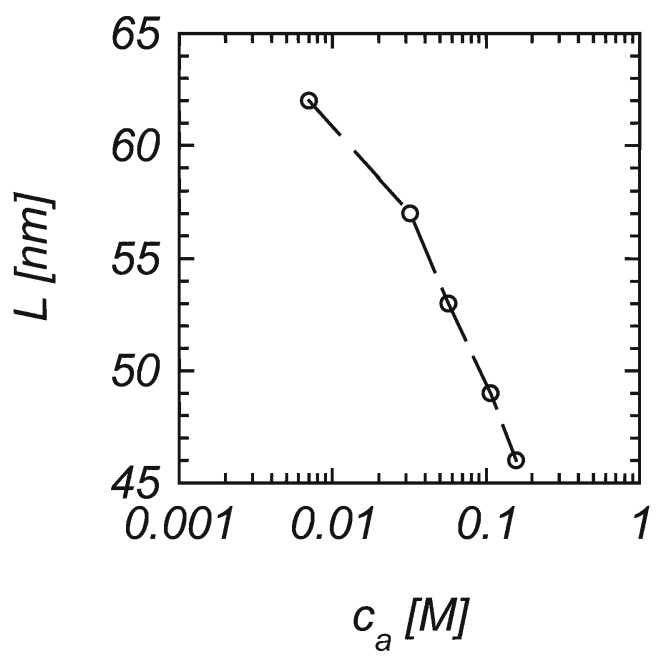

Fig. 4 Influence of the ionic strength on the brush layer. The circles show the thickness $L$ of the brush layer as determined by the hydrodynamic radius $R_{\mathrm{H}}$. thickness $L$ of the surface layer shrinks drastically (see also ref. 24 and 25). Here $L$ was obtained from the hydrodynamic radius of latex $\mathrm{KpS13}$ ( $c f$. Table 1) in aqueous solution by dynamic light scattering. ${ }^{24,25}$ At low ionic strength the chains attached to the surface are stretched to nearly full length. There is a marked shrinking of the surface layer upon raising the ionic strength in the system.

The above data point to the fact that the thickness of the brush layer can hence be well understood from the fact that the counterions are confined within the brush. ${ }^{22,24,25}$ This immediately leads to the conclusion that the $\mathrm{pH}$ inside the brush may be markedly different from the $\mathrm{pH}$ outside the brush. We will first discuss the simplest case of a quenched SPB where the number of charges per chain is independent of the $\mathrm{pH}$ in the system (see ref. 25 for further discussion). Hence, in this case the protons present in the solution act as counterions. Their concentration, $c_{\mathrm{a}}$, defines the $\mathrm{pH}$ outside which has been adjusted by the buffer solution. The $\mathrm{pH}$ inside the brush layer is then solely defined by the average activity of the counterions. In case of quenched brushes the $\mathrm{pH}$ within the brush is therefore much lower than the $\mathrm{pH}$ adjusted outside. This has been shown and discussed in detail by Birshtein and Zhulina. $^{33}$

For the annealed brushes under consideration here that consist of PAA chains, the $\mathrm{pH}$ within the brush is also determined by dissociation equilibrium between the carboxyl groups and protons. In this way $\left[\mathrm{H}^{+}\right]$is lowered considerably and the $\mathrm{pH}$ raised concomitantly. The $\mathrm{pH}$ resulting at low concentrations of added salt and/or buffer, however, is again given by the $\mathrm{pH}$ that is adjusted in a solution of free PAA-chains of the same concentration. Given the $\mathrm{p} K_{\mathrm{a}}$ of PAA of 4.6 and typical concentrations of PAA within the brush layer, a $\mathrm{pH}$ of $c a .3$ would result. A more realistic estimate starts from the assumption that one-half of the protons within the brush is replaced by the $\mathrm{Na}^{+}$ions of the MES buffer. This gives a $\mathrm{pH}$ of 4.6 , which is considerably lower than the $\mathrm{pH}=6.1$ of the solution. Raising the concentration of added salt will suppress this effect since there is no confinement of the counterions anymore in the limit of a salted brush.

Evidently, the $\mathrm{pH}$ cannot be a constant throughout the brush layer but will also depend on the distance from the surface of the particles. Moreover, annealed brushes exhibit subtle charge annealing effects that have been discussed in detail recently (see the discussion of this problem in ref. 25). For the qualitative understanding of the present results, however, a small variation of the $\mathrm{pH}$ within the brush may well be neglected. It suffices to deduce that the average $\mathrm{pH}$ within the brush is in the range of the isoelectric point of BSA if the salt concentration in the system is low. At high salt concentration the $\mathrm{pH}$ within the brush coincides with the $\mathrm{pH}$ adjusted by the buffer.

\section{Adsorption of BSA at different ionic strengths and $\mathrm{pH}$}

The experimental procedure used here is depicted in Fig. 2: The SPB solutions with adjusted $\mathrm{pH}$ and known ionic strength are mixed with BSA solution of equal ionic strength and $\mathrm{pH}$. Since the process of an equilibration may be slow and hence time-dependent, all mixtures were stirred for $24 \mathrm{~h}$. Then the non-adsorbed protein was removed by ultrafiltration against a salt solution with the same concentration and $\mathrm{pH}$. The amount of protein which is removed in this step could be determined quantitatively. In this way the amount of bound protein can be determined from the mass balance. Additional experiments were done in which the time used for equilibration was prolonged. No influence on the resulting adsorption was found. This demonstrates that the entire system has reached a well-defined state.

Fig. 5 to Fig. 8 display the principal results of this study. In Fig. 5 the amount of adsorbed BSA $\tau_{\text {ads }}$ per unit mass of the 


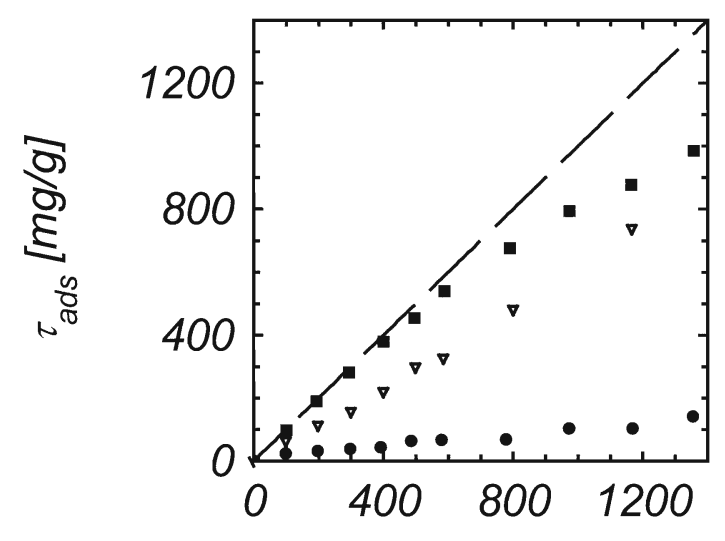

$B S A$ added [mg/g SPB]

Fig. 5 Adsorption of BSA on the SPB KpS13 at $\mathrm{pH}=6.1$ and a concentration of the MES buffer of $10 \mathrm{mM}$. The amount of adsorbed protein $\tau_{\text {ads }}$ per unit mass of the particles is plotted against the total amount of BSA normalized to the mass of the particles. The concentration of the particles was $10 \mathrm{mg} \mathrm{mL}^{-1}$ in each run. A parameter of the different curves is the concentration of added salt adjusted by adding $\mathrm{NaCl}$. Filled squares: no added salt $(7 \mathrm{mM})$; triangles: $57 \mathrm{mM}$; filled circles: $157 \mathrm{mM}$.

particles is plotted against the total amount of protein normalized to the mass of the added particles. The concentration of particles was $1 \mathrm{wt} \% \%$ in all runs. Fig. 6 gives the same data in a plot of $\tau_{\text {ads }}$ versus the concentration of BSA left in the solution. The $\mathrm{pH}$ was adjusted to 6.1 for all solutions by addition of $10 \mathrm{mM}$ MES buffer. Fig. 7 gives the data obtained for two different concentrations of the buffer at the same $\mathrm{pH}$. Fig. 8 finally shows the influence of different $\mathrm{pH}$ values in the solution while keeping the ionic strength constant $(12 \mathrm{mM})$.

Fig. 5 and 6 immediately demonstrate that BSA is strongly adsorbed if the ionic strength in the system is low while virtually no adsorption takes place for high ionic strength. This is opposite to the usual finding that a high ionic strength furthers the adsorption of proteins to polymeric surfaces. ${ }^{1}$ In the case of flat substrates the high ionic strength lowers the electrostatic repulsion between the surface and the dissolved

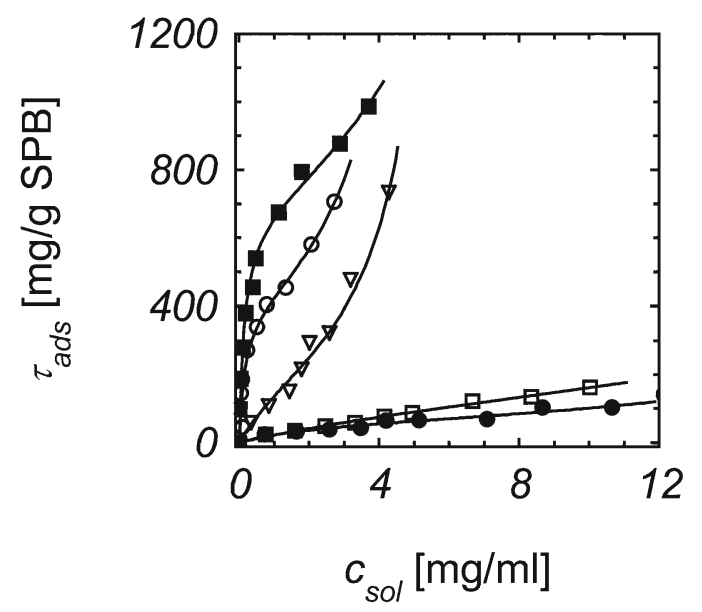

Fig. 6 Adsorption of BSA on the SPB $\mathrm{KpS13}$ at $\mathrm{pH}=6.1$ and at a concentration of the MES buffer of $10 \mathrm{mM}$. The amount of adsorbed BSA $\tau_{\text {ads }}$ per unit mass of the particles is plotted against the concentration of the protein left unadsorbed in solution. The data has been taken from the data shown in Fig. 5. Parameter of the different curves is the concentration of added salt $(\mathrm{NaCl})$. Filled squares: no added salt ( $7 \mathrm{mM}$ ); hollow circles: $32 \mathrm{mM}$; triangles: $57 \mathrm{mM}$; hollow squares: 107 $\mathrm{mM}$; filled circles: $157 \mathrm{mM}$. The lines show the fits of the data by eqn. (1).

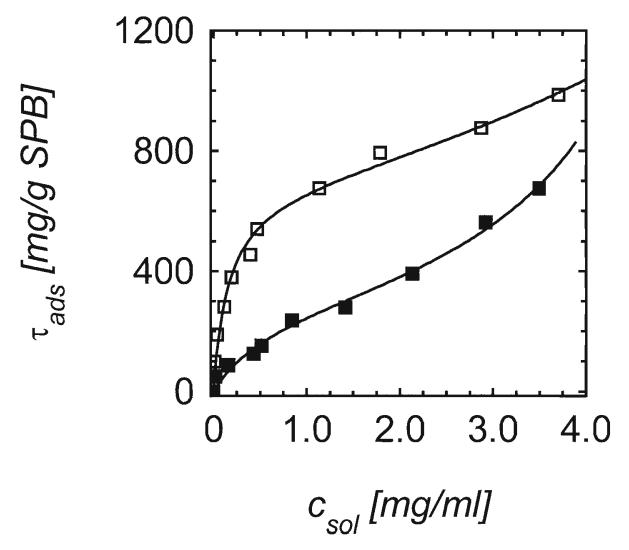

Fig. 7 Influence of the buffer concentration on the adsorption of BSA onto the spherical polyelectrolyte brushes. The amount of adsorbed BSA $\tau_{\text {ads }}$ per unit mass of the particles is plotted against the concentration of the protein left unadsorbed in solution. The open squares refer to a buffer concentration of $10 \mathrm{mM}$ MES whereas the filled squares refer to $50 \mathrm{mM}$ MES.

protein. The same repulsion should operate in the present mixtures, too, and an increased adsorption is to be expected at high ionic strength. Conversely, a low ionic strength is expected to prevent adsorption of dissolved proteins because both the protein and the particle are negatively charged. Moreover, the layer of densely grafted polymer chains, i.e., the brush layer on the surface of the particles should exert a strong steric repulsion onto the protein molecules that can be envisaged as small colloidal particles. The steric repulsion between solute objects and planar or curved brushes is a well-known phenomenon and no adsorption is expected for the present mixtures at all ( $c f$. the discussion of this point in ref. 26).

The experiments done at higher buffer concentrations displayed in Fig. 7 can now be explained by a higher ionic strength introduced by the higher buffer concentration. This shows clearly that the buffer present in the system adjusts the $\mathrm{pH}$ but influences the process of adsorption mainly via an increased ionic strength.

Fig. 8 displays the results obtained at different $\mathrm{pH}$. Here the $\mathrm{pH}$ has been adjusted around the optimal point of 6.1 of the MES buffer used in all experiments. At the same time the ionic strength was kept constant to $12 \mathrm{mM}$ by adding the respective

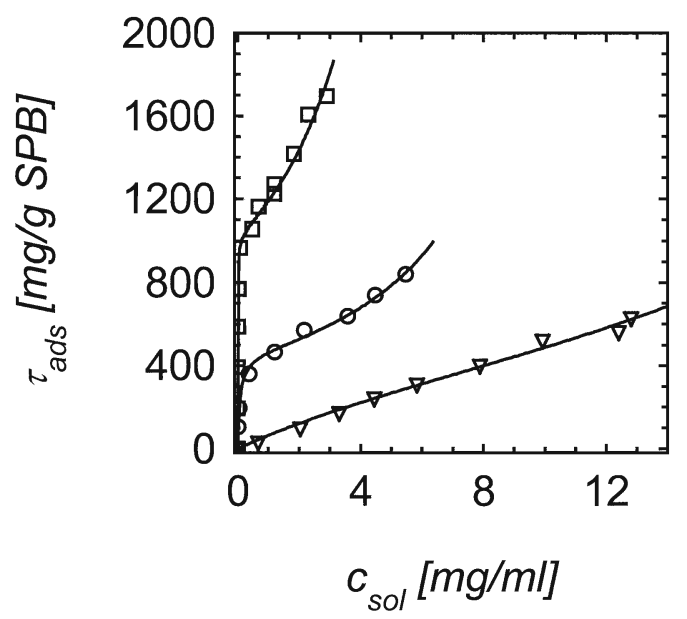

Fig. 8 Influence of $\mathrm{pH}$ on the adsorption of BSA onto the spherical polyelectrolyte brushes. The amount of adsorbed BSA $\tau_{\mathrm{ads}}$ per unit mass of the particles is plotted against the concentration of the protein left unadsorbed in solution. The open squares refer to $\mathrm{pH}=5.1$; the open circles to $\mathrm{pH}=6.1$, and the triangles refer to $\mathrm{pH}=7.2$. In all cases a buffer concentration of 10 mM MES was adjusted. 
amount of $\mathrm{NaCl}$. The data demonstrate that raising the $\mathrm{pH}$ to well above the isoelectric point of BSA (5.1) diminishes the effect while a much stronger adsorption is seen when approaching the isoelectric point of the protein. This is to be expected since the surface charge of the protein will become more negative when raising the $\mathrm{pH}$. The stronger repulsion between the SPB and the dissolved BSA is expected to lower the adsorption considerably. ${ }^{1,2}$ Moreover, the mutual repulsion among the adsorbed BSA molecules hampers the process of adsorption. Fig. 8 demonstrates, however, that there is a strong adsorption of BSA even at a $\mathrm{pH}$ of 7.2. The $\mathrm{pH}$ is hence an important but not decisive parameter for the process of adsorption.

Additional experiments demonstrate that the adsorption onto SPB is not only occurring for BSA but for other proteins as well. A detailed study along the lines devised here is underway but it is clear that the adsorption of dissolved proteins onto spherical polyelectrolyte brushes is a general phenomenon. All data available by now show that the decisive parameter is the ionic strength, the $\mathrm{pH}$ only modifies the strength of adsorption.

The latter point finds further support by the following observation. The bound protein can be washed off the particles by a salt solution of much higher ionic strength. Thus, flushing the particles carrying BSA by a $\mathrm{NaCl}$ solution of $0.5 \mathrm{M}$ concentration removes the protein quantitatively. This is a very important observation inasmuch as it shows that the adsorption is not irreversible. It may be reversed upon increasing the ionic strength to values where the electrostatic interaction play no role anymore. In this way the SPB present a new class of carrier particles whose interaction with proteins can be adjusted by the ionic strength.

\section{Modelling of the process of adsorption}

The modelling of the data shown in Figs. 5 to 8 must hence proceed from the following experimental facts: (i) the amount of adsorbed protein is mainly determined by the ionic strength; and (ii) the amount of adsorbed protein is related to the concentration of protein present in the solution during the process of adsorption. Point (i) will be discussed below. Here the modelling of the dependence on protein concentration is developed.

In principle, the adsorbed protein should be washed out again by ultrafiltration if the BSA would be bound to the particles by a one-step equilibration. This is not the case. The method employed here (see Fig. 2) shows that the adsorbed protein may be divided into a free and in a firmly bound fraction. Only the latter fraction remains bound so that it cannot be washed away in the last step. Fig. 6 to 8 are therefore no true adsorption isotherms but only compare these two fractions to each other. A modelling of the process of adsorption must hence be divided into two distinct steps: (i) the first step is an equilibration of the free and the bound protein; (ii) the adsorbed protein is rearranged within the brush so that the process of desorption becomes slow on the time scale of the present experiment

Step (i) can be modelled in terms of the usual adsorption isotherms used so far for the modelling of protein adsorption. We find that a model akin to the usual BET-isotherm gives the best description of the data. ${ }^{34}$ In the derivation of this model we assume that in this step the amount of adsorbed protein is proportional to the amount of free protein. Moreover, multiple layers of proteins may be adsorbed but with different probability. If the probability of the adsorption of a protein molecule onto the first layer is given by $z w_{\mathrm{ads}} \mathcal{c}_{\mathrm{sol}}$, with $z>1$, the probability for the adsorption of subsequent layers is only $w_{\mathrm{ads}} \mathcal{c}_{\mathrm{sol}}$. Since all experiments have been done at a given concentration of particles the adsorption of proteins can directly be discussed in terms of the adsorbed amount $\tau_{\text {ads }}$ as opposed to the concentration of the free protein $\mathcal{C}_{\mathrm{sol}}$ left in solution.
Table 2 Modelling of the adsorption of BSA to spherical polyelectrolyte brushes according to eqn. (1)

\begin{tabular}{|c|c|c|c|c|c|}
\hline SPB & $\begin{array}{l}\text { MES conc., } \\
\text { pH }\end{array}$ & $\begin{array}{l}\text { Ionic } \\
\text { strength }\end{array}$ & $\begin{array}{l}\tau_{\mathrm{ads}, \mathrm{M}} / \\
\mathrm{mg} \mathrm{g}^{-1} \mathrm{SPB}\end{array}$ & $z$ & $\begin{array}{l}w_{\mathrm{ads}} / \\
\mathrm{ml} \mathrm{mg}\end{array}$ \\
\hline $\mathrm{KpS13}$ & $10 \mathrm{mM}, \mathrm{pH} 6.1$ & $7 \mathrm{mM}$ & 682 & 71 & 0.091 \\
\hline $\mathrm{KpS13}$ & $10 \mathrm{mM}, \mathrm{pH} 6.1$ & $32 \mathrm{mM}$ & 400 & 38 & 0.165 \\
\hline $\mathrm{KpS13}$ & $10 \mathrm{mM}, \mathrm{pH} 6.1$ & $57 \mathrm{mM}$ & 253 & 1 & 0.161 \\
\hline $\mathrm{KpS13}$ & $10 \mathrm{mM}, \mathrm{pH} 6.1$ & $107 \mathrm{mM}$ & 176 & 5 & 0.029 \\
\hline $\mathrm{KpS13}$ & $10 \mathrm{mM}, \mathrm{pH} 6.1$ & $157 \mathrm{mM}$ & 69 & 11 & 0.040 \\
\hline $\mathrm{KpS13}$ & $50 \mathrm{mM}, \mathrm{pH} 6.1$ & $27 \mathrm{mM}$ & 303 & 10 & 0.168 \\
\hline $\mathrm{KpS14}$ & $10 \mathrm{mM}, \mathrm{pH} 6.1$ & $7 \mathrm{mM}$ & 770 & 279 & 0.069 \\
\hline $\mathrm{KpS14}$ & $10 \mathrm{mM}, \mathrm{pH} 5.1$ & $12 \mathrm{mM}$ & 1022 & 1328 & 0.145 \\
\hline $\mathrm{KpS14}$ & $10 \mathrm{mM}, \mathrm{pH} 6.1$ & $12 \mathrm{mM}$ & 449 & 159 & 0.086 \\
\hline $\mathrm{KpS14}$ & $10 \mathrm{mM}, \mathrm{pH} 7.2$ & $12 \mathrm{mM}$ & Undefined & Undefined & $\rightarrow 0$ \\
\hline
\end{tabular}

$\tau_{\mathrm{ads}, \mathrm{M}}$ : maximum mass of protein molecules per unit mass of particles for the first adsorbed layer; $z, w_{\text {ads }}$ : parameters characterising the strength of adsorption in eqn. (1)

Going along the usual lines, the resulting isotherm may be derived as

$$
\frac{\tau_{\mathrm{ads}}}{\tau_{\mathrm{ads}, \mathrm{M}}}=\frac{z w_{\mathrm{ads}} \mathcal{c}_{\mathrm{sol}}}{\left(1-w_{\mathrm{ads}} \mathcal{c}_{\mathrm{sol}}\right)\left[1+(z-1) w_{\mathrm{ads}} \mathcal{c}_{\mathrm{sol}}\right]}
$$

where $\tau_{\mathrm{ads}, \mathrm{M}}$ denotes the maximum mass of protein needed for the first adsorbed layer. Using this expression all data obtained so far can be modelled in terms of three parameters, namely $w_{\mathrm{ads}}, z$, and $\tau_{\mathrm{ads}, \mathrm{M}}$. The lines in Fig. 6,7 and 8 show the optimal fits of the respective data. Table 2 gathers the data deriving from these fits. It is evident that these data do not describe a true equilibrium state. Therefore they cannot be interpreted as thermodynamic data.

Evidently, eqn. (1) gives an excellent description despite the fact that $\tau_{\text {ads }}$ does not refer to a true equilibrium state. Moreover, the fits of eqn. (1) to the present experimental data shown in Fig. 6 to 8 demonstrate that multilayer adsorption occurs in these systems. This becomes also evident when considering the geometry of the particles in relation to the number of the adsorbed BSA molecules and their approximate size. BSA has in solution a hydrodynamic radius of $3.5 \mathrm{~nm} .{ }^{36}$ Here it becomes evident that the high number of protein molecules can only be accommodated within the brush if multilayer adsorption is assumed. Thus, the highest amount adsorbed (at $10 \mathrm{mM}$ buffer concentration without added salt; see Table I) corresponds to a number of protein molecules that exceeds the number adsorbed in a monolayer attached directly to the surface by the factor of 5 . This finding clearly demonstrates that the present particles exhibit a high capacity of adsorption for BSA that exceeds that of a single layer by far.

Close inspection of Table 2 as well as of Fig. 6 reveals that raising the salt concentration leads to a weaker adsorption of the first monolayer. However, the tendency of multilayer adsorption is increased upon increasing the ionic strength within the system. This points to a non-negligible interaction of the adsorbed protein molecules within the brush layer which leads to an increased binding strength for the second and all subsequent layers.

\section{Interaction of proteins with spherical polyelectrolyte brushes}

The foregoing discussion therefore suggests that the two-step model suggested above must be a valid description of the process of adsorption. Evidently, the first step must be connected to an adsorption/desorption equilibrium which in turn leads to the well defined isotherm-like adsorption curves shown in Fig. 6 to 8 . This first step must also define the number of available places on brush particles at a given ionic strength. In a subsequent step the binding of the BSA becomes much stronger so that the subsequent washing process ( $c f$. Fig. 2) does not 
remove the bound protein. The second step, however, does not change the structure achieved in the first step in which the proteins are adsorbed, no protein is adsorbed or desorbed anymore. If these two steps are not be well separated, there will be no direct connection between $\tau_{\mathrm{ads}}$ and $\mathcal{c}_{\text {sol }}$ found in the above modelling of the data.

The second step cannot be related to the total unfolding of the secondary structure. Such a process would lead to an irreversible adsorption of the protein and a washing off by salt solution would no more be possible. Measurements of the circular dichroism of the BSA washed off the particles, again show that only small changes of the secondary structure have been effected by the process of adsorption. ${ }^{35}$ Hence, there can only be a small conformational change when BSA is adsorbed onto the SPB.

The fact that protein adsorption onto flat solid substrates is related to a slow kinetics is well-known in literature. ${ }^{20,37}$ It can be explained by a rearrangement of the adsorbing protein molecules on the flat surface that can be modelled in terms of a "growing disk" model ${ }^{38,39}$ or by other models that take into account the mutual roll-over or displacement of the molecules. ${ }^{40,41}$ It must be kept in mind, however, that these models have been developed for planar flat surfaces. The surface of the present particles is dominated by the brush layer and the interaction of proteins with this layer must be decisive. Moreover, from the grafting density an average distance between the attached polyelectrolyte chains may be derived to be of the order of $3 \mathrm{~nm}$. The hydrodynamic diameter of BSA in solution is $c a .7 \mathrm{~nm}^{36}$ It is therefore obvious that BSA can hardly touch the surface as is the case in bare colloidal particles. We also reiterate that the amount of adsorbed BSA would correspond to a multi-layer adsorption for unmodified poly(styrene) particles. Hence, possible rearrangements of the protein molecules in the brush that must be held responsible for the kinetics of the process can hardly be described in terms of these models.

The above discussion has demonstrated that the adsorption of BSA and other proteins to the SPB must mainly be related to the electrostatic interaction of the polyelectrolyte chains with the surface of the proteins. All findings can be explained as follows:

1. One driving force for the adsorption is related to the different $\mathrm{pH}$ within the brush as opposed to the $\mathrm{pH}$ adjusted by the buffer outside the particles. The $\mathrm{pH}$ is considerably lower inside the layer than outside. Only at high concentration of added salt the $\mathrm{pH}$ inside and outside coincide. Hence, if the $\mathrm{pH}$ within the brush is approaching the isoelectric point of the protein (5.1 for BSA), the electrostatic repulsion between the brush particle and the protein is lowered or vanishes totally. Thus, the adsorption is indirectly related to the strong interaction of the linear polyelectrolytes which form a brush on the surface of the particles. This effect would not exist in solutions of single linear polyelectrolyte chains and proteins.

2. The linear polyelectrolyte chains can interact with the positive charges on the surface of the protein molecules. Depending on the number of these positive patches the interaction may be more or less strong. Thus, the positive patch of the protein becomes a multivalent counterion which neutralizes several negative charges of the linear polyelectrolyte chain. The activity of the counterions within a brush, however, is quite low and even monovalent counterions are mainly confined within the brush. ${ }^{32}$ For multivalent counterions this effect becomes even stronger. For each neutralized patch the respective negative counterions together with the positive counterions of the PAA chains are released. This is connected to a concomitant gain of entropy of the entire system. If the proteins were to be released from the brush again, the concomitant number of counterions must be brought back to the brush. The loss of entropy related to such a process renders it much less probable and the proteins are bound tightly to the brush ("counterion release force"; see the discussion in ref. 42). This would also explain the strong adsorption of BSA that persists if the ionic strength in the solution is kept constant-the activity of the protein molecules serving as counterions is dropped to very low values and the equilibrium concentration of the proteins outside is in consequence negligibly small. If salt is added, however, the effect vanishes and the protein molecules are replaced by the ions of the added salt.

\section{Conclusion}

A study of the adsorption of BSA onto spherical polyelectrolyte brushes has been presented. Strong adsorption of BSA onto the SPB is observed at low ionic strength despite the effect that the particles as well as the dissolved BSA are charged negatively. The adsorption of BSA decreases drastically with increasing amounts of added salt. The possible reasons for the strong adsorption are discussed: (i) a lower $\mathrm{pH}$ within the brush at low concentration of added salt; (ii) interaction of the polyelectrolyte chains with positive patches on the surface of the protein where the proteins become counterions ("counterion release force",42). At higher ionic strength the $\mathrm{pH}$ as well as the salt concentration within the brush will be the same as in the solution. Under these conditions the driving forces must vanish. The steric repulsion between the protein and the brush layer becomes operative and no adsorption takes place. Under these circumstances the SPB studied here resemble the brushes set up from uncharged hydrophilic polymers like poly(ethyleneoxide). ${ }^{43}$

These hypotheses are underlined by the fact that the proteins can be washed off easily by salt solution. All results presented here therefore demonstrate that the SPB present a new class of carrier particles the interaction of which with proteins may be tuned by the ionic strength. Additional studies performed with other proteins are underway by now. Possible applications for the separation of proteins are at hand and will be pursued in due course.

\section{Acknowledgements}

Financial support by the Deutsche Forschungsgemeinschaft, Schwerpunkt "Polyelektrolyte", and by the Roche Diagnostics Company is gratefully acknowledged. The authors are indebted to C. Czeslik for helpful discussions.

\section{References}

1 Proteins at Interfaces II, ACS Symposium Series 602, ed T. A. Horbett and J. L. Brash, American Chemical Society, Washington, DC, 1995

2 E. Ostuni, R. G. Chapman, R. E. Holmlin, S. Takayama and G. M. Whitesides, Langmuir, 2001, 17, 5605 and further references gives therein.

3 H. Kawaguchi, Prog. Polym. Sci., 2000, 25, 1171

4 C. Czeslik and R. Winter, Phys. Chem. Chem. Phys., 2001, 3, 235 G. Jackler, R. Steitz and C. Czeslik, Langmuir, 2002, 18, 6565.

5 C. E. Giacomelli and W. Norde, J. Colloid Interface Sci., 234, 233 Sci. 2001.

6 W. Norde and J. Lyklema, J. Colloid Interface Sci., 1978, 66, 257.

7 W. Norde and J. Lyklema, J. Colloid Interface Sci., 1978, 66, 266.

8 W. Norde and J. Lyklema, J. Colloid Interface Sci., 1978, 66, 277 .

9 W. Norde and J. Lyklema, J. Colloid Interface Sci, 1978, 66, 285

10 W. Norde and J. Lyklema, J. Colloid Interface Sci., 1978, 66, 295.

11 J. M. Peula and F. J. de las Nieves, Colloids Surf., A, 1993, 77, 199 .

12 J. M. Peula, J. Callejas, F. J. de las Nieves, in Surface Properties of Biomaterials, ed. R. West, G. Batts, Butterworth-Heinemann, Manchester, 1994.

13 J. M. Peula and F. J. de las Nieves, Colloids Surf., A, 1994, 90, 55. 
14 C. A. Giacomelli, A. W. P. Vermeer and W. Norde, J. Colloid Interface Sci, 2000, 231, 283.

15 J.-Y. Yoon, H.-Y. Park, J.-H. Kim and W.-S. Kim, Colloid Interface Sci., 1996, 177, 613.

16 J. H. Lee, J.-Y. Yoon and W.-S. Kim, Biomed. Chromatogr., 1998, 12,330 .

17 J.-Y. Yoon, J. H. Lee, J.-H. Kim and W.-S. Kim, Colloids Surf,, $B, 1998,10,365$

18 J.-Y. Yoon, J.-H. Kim and W.-S. Kim, Colloids Surf., A, 1999, $153,413$.

19 J.-T. Oh and J.-H. Kim, Enzyme Microb. Technol., 2000, 27, 356.

20 T. Vermonden, C. E. Giacomelli and W. Norde, Langmuir, 2001, 17,3734 .

21 J. D. Andrade, in Surface and Interfacial Aspects of Biomedical Polymers, ed. J. D. Andrade, Plenum, New York, 1985, vol. 2, Protein Adsorption.

22 P. Pincus, Macromolecules, 1991, 24, 2912

23 X. Guo, A. Weiss and M. Ballauff, Macromolecules, 1999, 32, 6043.

24 X. Guo and M. Ballauff, Langmuir, 2000, 16, 8719.

25 X. Guo and M. Ballauff, Phys. Rev. E: Stat. Phys., Plasmas, Fluids, Relat. Interdiscip. Top., 2001, 64, 51406.

26 Y. Tran, P. Auroy, L.-T. Lee and M. Stamm, Phys. Rev. E: Stat. Phys, Plasmas, Fluids, Relat. Interdiscip. Top., 1999, 50, 6984.

27 G. Decher, Science, 1997, 277, 1232 and further citations given there.

28 T. Kawai, K. Sugita, K. Saito and T. Sugo, Macromolecules, 2000, 33, 1306 and further citations given therein.
29 I. Koguma, K. Sugita, K. Saito and T. Sugo, Biotechnol. Progr, $2000,16,456$.

30 T. Kawai, M. Nakamura, T. Sugita, K. Saito and T. Sugo, Biotechnol. Progr., 2001, 17, 872.

31 K. Saito, Sep. Sci. Technol, 2002, 37, 535 and further citations given there.

32 B. Das, X. Guo and M. Ballauff, Prog. Colloid Polym. Sci, 2002, $121,34$.

33 T. M. Birshtein and E. B. Zhulina, Ber. Bunsen-Ges. Phys. Chem, 1996, 100, 929 .

34 S. Brunauer, P. Emmet and E. Teller, J. Am. Chem. Soc., 1938, 60, 309 .

35 G. Jackler, A. Wittemann, M. Ballauff, C. Czeslik, in preparation.

36 I. Axelsson, $J$. Chromatogr., 1978, 152, 21.

37 C. F. Wertz and M. M. Santore, Langmuir, 2002, 18, 706 and further references given there.

38 M. C. P. van Eijk and M. Cohen Stuart, Langmuir, 1997, 13, 5447.

39 E. Pefferkorn and A. Elaissari, J. Colloid Interface Sci, 1990 $138,187$.

40 C. F. Wertz and M. M. Santore, Langmuir, 2002, 18, 1190

41 W. Norde and C. E. Giacomelli, Macromol. Symp., 1999 , $145,125$.

42 C. Fleck and H. H. von Grünberg, Phys. Rev. E: Stat. Phys., Plasmas, Fluids, Relat. Interdiscip. Top., 2001, 63, 61.

43 See the discussion of these systems in E. P. K. Currie, J. van der Gucht, O. V. Borisov and M. A. Cohen Stuart, Pure Appl. Chem., $1999,71,1227$. 